\section{OPEN ACCESS}

\title{
Prevalence of Bullying in Grassroots Soccer in Spain: Victims, Bullies, and Bystanders \\ Bullying in Grassroots Soccer in Spain: Victims, Bullies, and Bystanders
}

\author{
Authors' contribution: \\ A) conception and design \\ of the study \\ B) acquisition of data \\ C) analysis and interpretation \\ of data \\ D) manuscript preparation \\ E) obtaining funding
}

Received: 16.06 .2021

Accepted: 02.11.2021

\author{
Xènia Ríos ${ }^{1 A-D}(\mathrm{D})$, Carles Ventura*1A-E (D), Teresa Lleixà ${ }^{2 A-D}$ (D), \\ Maria Prat ${ }^{3 A-D}$ (D), Gonzalo Flores ${ }^{4 A-D}$ iD \\ ${ }^{1}$ National Institute of Physical Education of Catalonia (INEFC), University of Barcelona \\ (UB), Barcelona, Spain \\ ${ }^{2}$ Faculty of Education, University of Barcelona (UB), Barcelona, Spain \\ ${ }^{3}$ Faculty of Educational Sciences, Autonomous University of Barcelona (UAB), \\ Bellaterra, Spain \\ ${ }^{4}$ Faculty of Education Sciences, University of Sevilla, Spain
}

${ }^{*}$ Correspondence: Carles Ventura, National Institute of Physical Education of Catalonia (INEFC), University of Barcelona (UB). Anella Olímpica, Avinguda de l'Estadi 12-22, 08038 Barcelona, Spain; Email: carlesventura@gencat.cat

\begin{abstract}
Bullying is a social problem that has been studied most in schools but affects other social contexts. However, there is a general lack of studies on bullying in sports. The aim of this study was to determine the prevalence of bullying among youth soccer players. Participants were 1,980 soccer players $(88.2 \%$ boys $)$ aged 8 to 13 years $\left(\mathrm{M}_{\text {age }}=10.5, \mathrm{SD}=1.68\right)$ from 25 clubs in Catalonia, Spain. An ad hoc questionnaire was administered to analyze the prevalence and characteristics of bullying from the perspective of victims, bullies, and bystanders. The overall bullying victimization rate was $8.9 \%$, with higher rates observed in the younger categories $(p<.001) ; 5.2 \%$ of victims experienced bullying in both their soccer club and at school. The bullying and bystander rates were $14.8 \%$ and $34.7 \%$, respectively, with significant differences between boys and girls $(15.5 \%$ of boys and $9 \%$ of girls were bullies $[p<.05]$, while $36.4 \%$ of boys and $21.9 \%$ of girls were bystanders $[p<.001])$. Verbal bullying was the main type of bullying reported. The locker room and pitch were the most common locations, and victims were more likely to deal with bullying on their own than to ask for help. Bullying is present in grassroots soccer, and anti-bullying programs are needed to instill ethical and moral values in athletes and equip coaches with the necessary skills to prevent, detect, and address bullying situations.
\end{abstract}

Keywords: Bullying, soccer, sport, victimization, youth

\section{Introduction}

The earliest research into bullying, conducted by Olweus in the 1970s, focused on aggression in schools (Olweus, 1978). Research has grown in recent decades, and bullying is now considered a global problem present across cultures and socioeconomic classes (Nery et al., 2020). Bullying is defined as a specific type of peer aggression repeated over time that involves the intention to harm and an imbalance of power between the bully(s) and the vic$\operatorname{tim}(\mathrm{s})$ in which the victim(s) cannot easily defend themselves (Olweus, 2013). Traditional bullying can be physical (e.g., hitting), verbal (e.g., jeers), or social/relational (e.g., spreading rumors); bullying can be direct or indirect, depending on whether there is physical interaction (Olweus, 2006). Cyberbullying has appeared in more recent years 
with the growing use of new technologies (Smith, 2019b). Prevalence rates of 35\% and 15\% have been reported for traditional bullying and cyberbullying in the school environment, respectively (Modecki et al., 2014).

Although the bulk of bullying research has focused on schools, bullying is present in many other social contexts (Monks \& Coyne, 2011). Organized sports outside of the school environment offer opportunities for social interaction among peers and account for a considerable share of young people's leisure time (Jones et al., 2016). Sports provide numerous benefits for children and teenagers, promoting physical, psychological, and social development and helping prevent disease. If not accompanied by adequate educational processes, however, it can promote the emergence of negative behaviors, including bullying (Logan et al., 2019). An overly competitive environment with an excessive focus on winning can also provide a space for bullying, particularly among younger athletes (Menesini et al., 2018). This environment is often tolerated and accepted as part of the norm by the sports community (Nery et al., 2021). Prevalence rates for bullying among young athletes also vary widely according to methodological differences. In a study of bullying among young male athletes in different sports in Portugal, Nery et al. (2019) found a victimization rate of $10 \%$, a bullying rate of $11 \%$, and a bystander rate of $35 \%$. By contrast, Mishna et al. (2019) reported in a study of Canadian athletes corresponding rates of $48 \%, 31 \%$, and $62 \%$ for traditional bullying, and $7 \%, 9 \%$, and $15 \%$ for cyberbullying. Studies that have analyzed the same sample at school and in organized sports outside of school have reported a higher prevalence of bullying at school (Evans et al., 2016; Volk \& Lagzdins, 2009). Studies have also found that some students are targeted in both places, known as double victimization (Collot \& Dudink, 2010; Vveinhardt \& Fominiene, 2019). Risk factors for being bullied in sports include disability (Danes-Staples et al., 2013), obesity (Bacchini et al., 2015), belonging to an ethnic minority (Kentel \& McHugh, 2015) or sexual minority (Baiocco et al., 2018), and being less skilled (Kerr et al., 2016; Mishna et al., 2019; Vveinhardt et al., 2019b). Male athletes are more likely to bully and be bullied than female athletes (Vveinhardt \& Fominiene, 2019), and studies of team sports have found that boys are more likely to be pure bullies (Evans et al., 2016; Tilindienè et al., 2008), whereas girls are more likely to be both bullies and victims (Mishna et al., 2019). Verbal bullying is the most common form of bullying in sports, while cyberbullying is the least common; furthermore, the locker room is the place where most bullying occurs (Mishna et al., 2019; Nery et al., 2019). Bullying rates in sports have not been found to vary by age, but older athletes tend to engage in more subtle or indirect forms of bullying, such as social isolation or harming a person's reputation (Vveinhardt \& Fominiene, 2019).

Soccer is one of the most widely played sports, with 265 million practitioners worldwide (Kunz, 2007), and it is the most played sport by children and adolescents in Europe (Hulteen et al., 2017). However, no studies to date have analyzed the presence of bullying in such a widely played sport as soccer. This study aimed to analyze the prevalence of bullying in youth soccer in Catalonia, Spain from three perspectives - victims, bullies, and bystanders - and investigated additional factors such as emotions, places of occurrence, and the relationship between bullying in soccer clubs and at school. The results could be of interest to coaches, sports psychologists, and physical education providers as they provide insight into the reality of this phenomenon in sports and can contribute to the design of bullying prevention programs.

\section{Methods}

\section{Participants}

We studied 1,980 grassroots soccer players ( $88.2 \%$ boys) aged between 8 and 13 years $\left(\mathrm{M}_{\text {age }}=10.5\right.$ years, $\mathrm{SD}=$ 1.68) from 25 clubs across Catalonia, Spain. The sample included male and female soccer players from clubs across Catalonia with a margin of error of $2.9 \%$ and a confidence level of $99 \%$. Overall, $29.8 \%$ (80.3\% boys) played in the U9 category, $40.1 \%$ ( $89.1 \%$ boys) in the U11 category, and 30.1\% (94.8\% boys) in the U13 category. The vast majority (95.6\%) were born in Spain, $70.2 \%$ had been playing at the same soccer club for two or more seasons, $96.7 \%$ trained two or three days a week, and $6.2 \%$ played at the top level in their category.

\section{Measures}

Drawing on other questionnaires used to analyze bullying in sports (Adler, 2014; Evans et al., 2016; Martínez, 2016; Nery et al., 2019), we designed an ad hoc questionnaire to analyze the presence of bullying among young soccer players in clubs. The questionnaire was sent to a panel of experts - five men and two women, all with a $\mathrm{PhD}$ in physical activity and sports science - for validation. They were asked to rate the suitability of each item on a six-point Likert scale, ranging from 1 (not at all suitable) to 6 (very suitable). Interrater agreement was evaluated using Free-Marginal Multirater Kappa, and the resulting kappa value of .97 was considered satisfactory. The 
questionnaire was then piloted among 62 soccer players (3.2\% girls) from the same age categories as the target population. The players were informed about the purpose of the study and, after they agreed to participate, were asked to give their critical opinions on the content of the questionnaire. Their comments led to some minor modifications. The questionnaire items addressed bullying situations from the position of victims, bullies, and bystanders during the current and past soccer season. The first section included sociodemographic information (three items: gender, age, and birthplace) and details of soccer practice (four items: years playing soccer, number of training sessions per week, age category, and level of competition). The next section investigated experiences with being bullied. The players were asked how often they had experienced bullying at school (one item) or in the club (one item) in the past couple of months. Then, they were asked how often they had experienced different types of bullying situations, including verbal, physical, social, and cyberbullying, at their club (19 items). The options were "never," "sometimes" (only one or twice), "often" (two or three times a month), and "very often" (about once a week). Finally, they were asked where these situations had taken place (one item), how many people had bullied them (one item), how they had felt (one item: emotions), how they responded (one item: coping and communication strategies), and whether they had thought about leaving the team or club because of these incidents (one item). The third section was designed to gather information about bystander experiences in the past couple of months. Players were asked how often they had witnessed bullying situations in the club (one item). The options were "never," "sometimes" (only one or twice), "often" (two or three times a month), and "very often" (about once a week). In addition, players were asked how many players they had seen victimized (one item) and how they had felt and responded in such cases (one item). The fourth and final section was designed to analyze experiences with bullying from the perspective of the perpetrator. In this case, players were asked how often they had engaged in any bullying situations in the club (one item) or at school (one item). The options were "never," "sometimes" (only one or twice), "often" (two or three times a month), and "very often" (about once a week). Then we asked how they had felt (one item), why they had engaged in bullying (one item), and whether they had also engaged in bullying at school (one item). Questions about where bullying had occurred, how players felt about and responded to bullying situations, and reasons for bullying had multiple-choice options.

\section{Design and Procedure}

We performed a descriptive, cross-sectional study. The questionnaires were administered three months after the start of the soccer season. Once the clubs had agreed to participate, an informed consent form was sent to the parents/tutors of all the players explaining the set-up, purpose, and voluntary nature of the study and providing assurance of anonymity and confidentiality. Members of the research team then visited each club on a previously arranged date to administer the questionnaire. In most cases, it was completed before the start of training. Before asking the children to complete the questionnaire, the researcher explained what was meant by bullying and cyberbullying and gave some examples. The children were assured that their answers would be anonymous and treated confidentially. The players had been previously seated at a sufficient distance from each other to guarantee privacy. The study protocol was approved by the ethics committee of the Catalan Government's Sports Council (17/2019/CEICEGC). Signed informed consent from the players' parents or tutors was required in all cases.

\section{Statistical Analysis}

Descriptive statistics (frequencies and percentages) were used to report the data, and associations were analyzed using Pearson's chi-square test or the likelihood-ratio test, as appropriate. Statistical significance was set at a level of $p<.05$, and all analyses were performed in SPSS software (version 21.0).

\section{Results}

\section{Victims}

In total, $8.9 \%$ of players stated they had been bullied at their soccer club (7.4\% sometimes, $1.4 \%$ often, and $0.2 \%$ very often). No significant differences were observed for gender or level of competition. We did, however, observe a significant difference for the age category, with higher victimization rates in the younger categories: $13.4 \%$ in U9s, $8 \%$ in U11s, and $5.9 \%$ in U13s $\left(\chi^{2}[6, \mathrm{~N}=1978]=24.01, p<.001\right)$. Significant differences were also observed for place of birth, with a higher victimization rate among those born outside Spain $(14.9 \%$ vs. $8.7 \%$ for those born in Spain; $\left.\chi^{2}[3, \mathrm{~N}=1950]=8.01, p<.05\right)$. Concerning the interaction between place of birth and gender, 
$12.7 \%$ of boys born outside Spain reported having been bullied versus $9 \%$ of those born in Spain. The difference was even more pronounced for female players ( $25 \%$ vs. $6 \%)$. A significantly higher proportion of players reported having been bullied at school (19\%) than in the club $\left(\chi^{2}[9, \mathrm{~N}=1978]=326.43, p<.001 ; 15 \%\right.$ sometimes, $1.8 \%$ often, and $2.2 \%$ very often). Overall, $5.4 \%$ of respondents had been bullied in both places.

\section{Types of Bullying}

Verbal bullying (52.7\%) was the most common form of bullying experienced in clubs, followed by physical bullying (33.3\%), social bullying (15.9\%), and cyberbullying (7.1\%). Boys were more likely than girls to experience verbal bullying $\left(55.4 \%\right.$ vs. $\left.30.8 \% ; \chi^{2}[1, \mathrm{~N}=1972]=17.62, p<.001\right)$ and physical bullying $(35.7 \%$ vs. $15.5 \%$; $\left.\chi^{2}[1, \mathrm{~N}=1972]=37.77, p<.001\right)$. The numbers and percentages of victims by type of bullying are shown for the group as a whole and for boys and girls separately (together with statistical differences) in Table 1. In total, 22.6\% of players experienced just one type of bullying, $20.0 \%$ experienced two, $12.2 \%$ experienced three, and $2.7 \%$ experienced four; $42.5 \%$ of players did not experience bullying of any type.

Table 1. Frequency and percentage of types of bullying overall and by gender

\begin{tabular}{lccccccc}
\hline & \multicolumn{2}{c}{ Total } & \multicolumn{3}{l}{ Boys } & Girls & \\
\hline Type of bullying & $\mathrm{n}$ & $\%$ & $\mathrm{n}$ & $\%$ & $\mathrm{n}$ & $\%$ & $\chi^{2}(p)$ \\
\hline Verbal only & 378 & $19.17 \%$ & 330 & $18.98 \%$ & 48 & $20.60 \%$ & \\
Social only & 9 & $0.46 \%$ & 5 & $0.29 \%$ & 4 & $1.72 \%$ & $9.24(<.01)$ \\
Physical only & 52 & $2.64 \%$ & 47 & $2.70 \%$ & 5 & $2.15 \%$ & \\
Cyberbullying only & 7 & $0.35 \%$ & 6 & $0.35 \%$ & 1 & $0.43 \%$ & \\
Verbal \& social & 62 & $3.14 \%$ & 45 & $2.59 \%$ & 17 & $7.30 \%$ & $14.96(<.001)$ \\
Verbal \& physical & 307 & $15.57 \%$ & 294 & $16.91 \%$ & 13 & $5.58 \%$ & $20.06(<.001)$ \\
Verbal \& cyberbullying & 19 & $0.96 \%$ & 18 & $1.04 \%$ & 1 & $0.43 \%$ & \\
Social \& physical & 4 & $0.20 \%$ & 4 & $0.23 \%$ & 0 & $0.00 \%$ & \\
Social \& cyberbullying & 0 & $0.00 \%$ & 0 & $0.00 \%$ & 0 & $0.00 \%$ & \\
Physical \& cyberbullying & 3 & $0.15 \%$ & 1 & $0.06 \%$ & 2 & $0.86 \%$ & $4.99(<.05)$ \\
Verbal \& social \& physical & 182 & $9.23 \%$ & 172 & $9.89 \%$ & 10 & $4.29 \%$ & $7.69(<.01)$ \\
Verbal \& social \& cyberbullying & 3 & $0.15 \%$ & 3 & $0.17 \%$ & 0 & $0.00 \%$ & \\
Verbal \& physical \& cyberbullying & 54 & $2.74 \%$ & 51 & $2.93 \%$ & 3 & $1.29 \%$ & \\
Social \& physical \& cyberbullying & 1 & $0.05 \%$ & 1 & $0.06 \%$ & 0 & $0.00 \%$ & \\
Verbal \& social \& physical \& cyberbullying & 53 & $2.69 \%$ & 50 & $2.88 \%$ & 3 & $1.29 \%$ & \\
None & 838 & $42.49 \%$ & 712 & $40.94 \%$ & 126 & $54.08 \%$ & $14.51(<.001)$ \\
\hline Total & 1972 & $100.0 \%$ & 1739 & $100.0 \%$ & 233 & $100.0 \%$ & \\
\hline
\end{tabular}

Note: $\chi^{2}=$ Chi-squared test $;(p)=\mathrm{p}$-value.

The most common bullying situations involved insults (34\%), being told to shut up (30.6\%), negative comments about mistakes made while playing (29.5\%), hitting/kicking (20.4\%), and name-calling (15.3\%). Boys were significantly more likely than girls to be insulted $\left(\chi^{2}[3, \mathrm{~N}=1966]=30.07, p<.001\right)$; told to shut up $\left(\chi^{2}[3, \mathrm{~N}=1967]\right.$ $=9.53, p<.05)$; receive nasty comments about their skin color or religion $\left(\chi^{2}[3, \mathrm{~N}=1970]=8.83, p<.05\right)$, appearance $\left(\chi^{2}[3, \mathrm{~N}=1969]=17.10, p<.001\right)$, or sexual orientation $\left(\chi^{2}[3, \mathrm{~N}=1966]=9.13, p<.05\right)$; be deliberately hit or kicked $\left(\chi^{2}[3, \mathrm{~N}=1970]=27.84, p<.001\right)$; have objects thrown at them $\left(\chi^{2}[3, \mathrm{~N}=1970]=10.22, p<.05\right)$; be threatened $\left(\chi^{2}[3, \mathrm{~N}=1966]=9.34, p<.05\right)$; have things get broken or wet $\left(\chi^{2}[3, \mathrm{~N}=1970]=14.64, p<.05\right)$; or be deliberately locked in the locker room or shower $\left(\chi^{2}[3, \mathrm{~N}=1968]=10.45, p<.05\right)$. Most of the bullying situations occurred in the locker room (39.4\%) or on the pitch (38.0\% during training and $15.1 \%$ during a match), but bullying also occurred off the pitch (14.5\%), at school (10.1\%), and through digital technologies (the Internet/ mobile phones; $3.2 \%$ ). The breakdown by place and gender is shown in Table 2 . 
Table 2. Distribution (\%) of bullying episodes according to place of occurrence by gender

\begin{tabular}{lcccc}
\hline Place & Boys & Girls & $\chi^{2}(1,1072)$ & $p$-value \\
\hline Locker room & $41.3 \%$ & $21.9 \%$ & 14.87 & $<.001$ \\
School & $10.9 \%$ & $2.9 \%$ & 6.69 & $<.01$ \\
Pitch (training) & $37.1 \%$ & $47.6 \%$ & 4.42 & $<.05$ \\
Pitch (matches) & $13.9 \%$ & $26.7 \%$ & 12.12 & $<.001$ \\
\hline
\end{tabular}

Note: $\chi^{2}=$ Chi-squared test $;(p)=$ p-value.

The victims responded to bullying in different ways: they ignored the bully or bullies (42.4\%), asked them to stop (24.5\%), asked someone for help (coach, $11.5 \%$; family member, $7.5 \%$; teammate, $4.3 \%$; another friend, $3.6 \%)$, cried $(4.3 \%)$, or ran away (3.2\%).

\section{Bystanders}

Overall, $34.7 \%$ of players said that they had witnessed bullying at their club (29.9\% sometimes, $3.3 \%$ often, and $1.5 \%$ very often). Statistically significant differences were observed for gender $\left(36.4 \%\right.$ vs. $21.9 \% ; \chi^{2}[3, \mathrm{~N}=1972]$ $=20.59, p<.001)$, with a higher proportion of male bystanders. There were no differences for age category or level of competition. Girls were significantly more likely to feel sad $\left(37.2 \%\right.$ vs. $\left.21.6 \% ; \chi^{2}[1, \mathrm{~N}=684]=6.53, p<.05\right)$, angry $\left(31.4 \%\right.$ vs. $\left.15.2 \% ; \chi^{2}[1, \mathrm{~N}=684]=9.05, p<.01\right)$, or sorry for the victim $\left(64.7 \%\right.$ vs. $49.8 \% ; \chi^{2}[1, \mathrm{~N}=684]$ $=4.22, p<.05)$. When the bystanders were asked what they did when they saw someone being bullied, $42.3 \%$ said that they defended their teammate by trying to put a stop to the situation, $39.3 \%$ did nothing but felt bad, $19.1 \%$ asked an adult for help, $14.1 \%$ pretended not to see what was happening, $5.7 \%$ joined in, and $4.8 \%$ did nothing, but found it amusing. The only significant difference observed between boys and girls was for pretending not to see what was happening $\left(15 \%\right.$ vs. $\left.2 \% ; \chi^{2}[1, \mathrm{~N}=684]=6.66, p<.01\right)$. The most common action taken by bystanders in the younger age categories was to try and stop the situation $(46.6 \%$ for U9s and $47.3 \%$ for U11s vs. $33.5 \%$ for $\left.\mathrm{U} 13 \mathrm{~s} ; \chi^{2}[2, \mathrm{~N}=684]=11.60, p<.005\right)$. The older players were significantly more likely to do nothing but feel bad $\left(47.5 \%\right.$ vs. $32.7 \%$ for U9s and $37.3 \%$ for U11s; $\left.\chi^{2}[1, \mathrm{~N}=684]=10.76, p<.001\right)$. Significant differences were also observed for joining in $\left(8.7 \%\right.$ for U9s, $5.8 \%$ for U11s, and $2.5 \%$ for U13s; $\left.\chi^{2}[1, \mathrm{~N}=684]=7.93, p<.005\right)$ and asking an adult for help $\left(26.4 \%\right.$ for U9s, $21.6 \%$ for U11s, and $10.2 \%$ for U13s; $\left.\chi^{2}[1, \mathrm{~N}=684]=20.38, p<.001\right)$.

\section{Bullies}

Overall, $14.8 \%$ of the players stated that they had bullied someone (13.6\% sometimes, $0.8 \%$ often, and $0.4 \%$ very often). Boys were significantly more likely than girls to be bullies $\left(15.5 \% \mathrm{vs} .9 \% ; \chi^{2}[3, \mathrm{~N}=1963]=7.86\right.$, $p<.05)$. No significant differences were observed for age category or level of competition. The most common feelings mentioned were feeling bad (34\%), not feeling anything (28.5\%), feeling worried about being reprimanded $(21.3 \%)$, and feeling sorry for the person being bullied (20.3\%). Less common feelings were feeling amused (7.2\%), good $(6.2 \%)$, or superior $(2.4 \%)$. The only significant difference between boys and girls was feeling sorry for the victim, mentioned by $47.6 \%$ of girls and $18.2 \%$ of boys $\left(\chi^{2}[1, \mathrm{~N}=290]=10.39, p<.001\right)$. The main reasons given for engaging in bullying were "they provoked me" (39.5\%), "I don't know" (29.9\%), "they deserve it" (19.6\%), "it's fun" (3.4\%), "it makes me feel good" (3.4\%), "I'm superior/better than the others" (3.1\%), and "I'm jealous" $(2.7 \%)$. The only significant difference observed between genders was for the answer "I don't know," mentioned by $71.4 \%$ of boys and $26.8 \%$ of girls $\left(\chi^{2}[1, \mathrm{~N}=290]=18.50, p<.001\right)$. Overall, $20.9 \%$ of players admitted to bullying at school (18.75\% sometimes, $1.1 \%$ often, and $1.1 \%$ very often), and $9.5 \%$ engaged in bullying both at school and in their club $\left(\chi^{2}[1, \mathrm{~N}=1965]=389.59, p<.001\right)$.

\section{Bullying Profiles}

The different bullying profiles identified are shown in Table 3 for the group overall and by gender. We identified "pure" roles (i.e., players who were a bully, a victim, or a bystander) and combined roles (i.e., players who filled more than one role). In total, $2.8 \%$ of the players surveyed were pure victims (more girls), $4.3 \%$ were pure bullies (more boys), and $21.8 \%$ were pure bystanders (more boys). The most common combined profile was that of bully-bystander, while the least common was bully-victim; $2.5 \%$ of the players filled all three roles (victimbully-bystander). 
Table 3. Frequency and percentage of bullying profiles

\begin{tabular}{lccccccc}
\hline & \multicolumn{2}{c}{ Total } & \multicolumn{2}{c}{ Boys } & \multicolumn{3}{c}{ Girls } \\
\hline Role & $\mathrm{n}$ & $\%$ & $\mathrm{n}$ & $\%$ & $\mathrm{n}$ & $\%$ & $\chi^{2}(p)$ \\
\hline Pure victim & 56 & $2.8 \%$ & 44 & $2.5 \%$ & 9 & $3.9 \%$ & \\
Pure bully & 85 & $4.3 \%$ & 78 & $4.5 \%$ & 7 & $3.0 \%$ & $57.84(<.001)$ \\
Pure bystander & 429 & $21.8 \%$ & 394 & $22.8 \%$ & 34 & $14.7 \%$ & $7.91(<.01)$ \\
Victim \& bully & 13 & $0.7 \%$ & 12 & $0.7 \%$ & 1 & $0.4 \%$ & \\
Victim \& bystander & 59 & $3.0 \%$ & 55 & $3.2 \%$ & 4 & $1.7 \%$ & \\
Bully \& bystander & 144 & $7.3 \%$ & 133 & $7.7 \%$ & 10 & $4.3 \%$ & \\
Victim \& bully \& bystander & 49 & $2.5 \%$ & 46 & $2.7 \%$ & 3 & $1.3 \%$ & \\
None & 1135 & $57.6 \%$ & 968 & $56.0 \%$ & 164 & $70.7 \%$ & $18.20(<.001)$ \\
\hline Total & 1970 & $100.0 \%$ & 1730 & $100.0 \%$ & 232 & $100.0 \%$ & \\
\hline
\end{tabular}

Note: $\chi^{2}=$ Chi-squared test $;(p)=\mathrm{p}$-value.

\section{Discussion}

The main finding of this study was the presence of bullying in grassroots soccer. The prevalence of victimization observed (8.9\%) is similar to that reported for young male athletes in Portugal (Nery et al., 2019) and much lower than that observed in Canadian athletes (Mishna et al., 2019). These discrepancies could be due to methodological differences such as sample characteristics, definitions of bullying, and, most likely, the use of different measurement tools (Smith, 2019a). The lack of a standardized, validated instrument makes it difficult to compare different aspects of bullying in sports across countries. Bullying was less common in sports than at school in our series, which is in line with previous findings (Collot \& Dudink, 2010; Evans et al., 2016; Nery et al., 2019; Volk \& Lagzdins, 2009). At school, children are more exposed to potential bullying situations due to the amount of time they spend there and the higher number of interactions they have with other children or adolescents (Nery et al., 2021).

The most common type of bullying was verbal (e.g., insults, name-calling), perhaps because soccer involves close interactions and is played on a large field where many comments may not be heard by the coach. Young athletes are also exposed to negative comments about how they play during matches, particularly by members of other players' families (Sánchez-Romero et al., 2020). These comments can come to be seen as normal and even reiterated by players during training or matches (Flores et al., 2021; Prat et al., 2020). The second most common type of bullying observed was physical bullying. Soccer is a physical game and intentional acts of aggression could go unnoticed or be interpreted as being part of the game. In a study of bullying among young amateur athletes in organized sport, Vveinhardt and Fominiene (2019) found similar victimization rates for verbal bullying among male and female athletes and higher rates for physical bullying among males. Rates may vary depending on how the data are analyzed. In our series, for example, we found no significant difference in the prevalence of pure verbal bullying between boys and girls, but the combination of verbal and physical bullying was much more common among boys. Our results may be related to gender role behavior, as soccer is an important contributor to the construction of masculine identity and can normalize and even reinforce certain negative behaviors such as verbal and physical bullying (Steinfeldt et al., 2012). Social bullying is probably less likely in sports than in other settings, particularly among younger athletes, as there are fewer opportunities for deliberately excluding a player from activities because coaches are largely responsible for forming groups. Cyberbullying was the least common type of bullying possibly because of the young age of the children (i.e., they would be less likely to be users of digital technologies; UNESCO, 2019) or because physical activities that involve competition can help develop defense mechanisms against cyberaggression (Benítez-Sillero et al., 2021).

In line with reports by Collot and Dudink (2010) and Vveinhardt and Fominiene (2019), our findings show that players can be bullied both at school and in organized sports. Schools and clubs should work together, particularly as many students, especially those living in rural areas, both go to school and play for clubs. Our findings show higher victimization rates among players born outside Spain, supporting reports of higher victimization among immigrant students due to cultural factors such as language, physical appearance, low social status, and limited peer 
support (Stevens et al., 2020). Bullying in sports and in physical education classes mostly occurs in locker rooms and playing areas (Mishna et al., 2019). Locker rooms are typically small spaces that provide ample opportunity for social interaction before or after training, normally without adult supervision (Kerr et al., 2016; Nery et al., 2020; Vveinhardt et al., 2019a). Insults and homophobic comments are common here, particularly among boys, and are often considered part of the norm (Iida \& McGivern, 2014). This, combined with the effects of peer pressure, can impose a code of silence ("what happens in the locker room stays in the locker room"), meaning coaches may often be unaware that bullying is taking place (Prat et al., 2020; Vveinhardt et al., 2019a). Victims of bullying generally try to cope on their own and rarely turn to others (e.g., teammates, family members, or coaches) for help (Collot \& Dudink, 2010; Nery et al., 2019; Vveinhardt et al., 2017); the main emotions reported were anger and sadness. Studies are needed on the short - and long-term psychological effects of being bullied and possible mood disorders such as depression and anxiety in later years (Moore et al., 2017). The bystander rate in our series is similar to that reported in other studies of bullying in sports (Nery et al., 2019; Vveinhardt et al., 2018) and at school (Callaghan et al., 2019; González-Cabrera et al., 2020) and shows that a considerable number of bullying situations are witnessed. The bystanders mostly reported negative emotions in relation to bullying; they were more likely to try to stop the situation themselves (direct action) than to ask an adult for help (indirect action), and some reported doing nothing. Sports clubs and teams should work on promoting emotional learning and development and strive to forge a climate that enhances group cohesion and friendship and encourages players to take direct or indirect action to put a stop to bullying situations.

The proportion of players who stated that they had engaged in bullying is similar to the rates reported by other researches (Nery et al., 2019; Vveinhardt \& Fominiene, 2019). We also found that boys were more likely to be bullies than girls (Evans et al., 2016; Tilindienè et al., 2008; Vveinhardt \& Fominiene, 2019), contrasting with reports by Mishna et al. (2019). The discrepancies are probably due to methodological and conceptual differences and highlight the need for a more exhaustive analysis of gender differences in different types of bullying and in bullying in general (Smith, 2019a). Bullying appears to be less common in sports than in schools, again probably because players spend much less time in clubs than at school and interact with fewer people in clubs. Negative emotions such as feeling bad or sorry for victims were more common than positive emotions such as feeling good, superior, or amused. The fact that bullies are aware of the negative effects of their actions is promising, as this awareness could be used in emotional learning programs to help young people recognize their emotions and link them to taking action.

Finally, all the bullying profiles except that of the pure victim were more common in boys than girls. In a study of Spanish adolescents, González-Cabrera et al. (2020) also found that girls were more likely to be pure victims. Girls may be better at recognizing and exposing bullying behaviors, whereas boys are more likely to feel a greater need to demonstrate their power (Vveinhardt \& Fominiene, 2019). Our results for the combined profile of victimbully-bystander are similar to those reported by Nery et al. (2019), but more research is needed on the prevalence of different roles, how they interact, and how they change over time (Smith, 2018).

\section{Conclusions}

The present study aimed to fill a gap in Spanish research on bullying in sports by determining the prevalence of bullying in organized youth soccer. Our findings confirm the presence of bullying in grassroots soccer, show its effects on victims, bullies, and bystanders, and identify links between different roles. One limitation of our study is that we surveyed young players currently playing club soccer, thereby potentially missing the experiences of players who might have already quit because of bullying. This problem could be overcome by conducting similar studies at schools, which would provide greater insights into the scope of bullying in soccer that could be integrated with findings from other sports to create a general map of the situation.

\section{Practical implications}

Drawing on Bronfenbrenner's ecological systems model (Bronfenbrenner, 1979) and its subsequent adaptation to bullying in sports by Nery et al. (2020), we propose a series of general actions and specific guidelines for analyzing, preventing, and addressing bullying in sports at the micro-, meso- exo-, and macro-levels. It is essential to create a climate of trust to break the code of silence that often exists within teams and to foster proper communication between players and their coaches (Evans et al., 2016; Volk \& Lagzdins, 2009). This can be done by designing programs that instill ethical and moral values in athletes (Gendron \& Frenette, 2016) and equip coaches with the 
skills needed to detect and address bullying situations (Collot \& Dudink, 2010; Mishna et al., 2019). It is encouraging that coaches have expressed interest in receiving training of this type (Flores et al., 2021); however, few programs targeting coaches exist (McCloughan et al., 2015). Meso-level actions should target families, who have also expressed concern about coaches' lack of preparation for dealing with bullying and the apparent lack of clear protocols (Flores et al., 2021). Exo-level actions should aim at creating regulatory frameworks and protocols within sports clubs and increasing awareness through the media. Finally, macro-level actions should seek to create statelevel legal structures and policies that foster education and to design, implement, and evaluate the effectiveness of anti-bullying programs.

\section{Ethics approval and informed consent}

The study protocol was approved by the ethics committee of the Catalan Government's Sports Council (17/2019/ CEICEGC).

\section{Competing interests}

The authors declare that there is no conflict of interest.

\section{Funding}

This work was supported by Barça Foundation and Institut Nacional d'Educació Física de Catalunya of the Generalitat de Catalunya under Grant PARINEFC 0003-2019.

\section{Acknowledgments}

We would like to thank all the players and their respective clubs for participating in this study.

\section{References}

Adler, A. L. (2014). An examination into bullying in the adolescent sport context. Unpublished doctoral thesis, Queen's University, Kingston, Ontario, Canada.

Bacchini, D., Licenziati, M. R., Garrasi, A., Corciulo, N., Driul, D., Tanas, R., Fiumani, P. M., Di Pietro, E., Pesce, S., Crino, A., Maltoni, G., Iughetti, L., Sartorio, A., Deiana, M., Lombardi, F., \& Valerio, G. (2015). Bullying and victimization in overweight and obese outpatient children and adolescents: An Italian multicentric study. PLoS ONE, 10(11), 1-10. https://doi.org/10.1371/journal.pone.0142715

Baiocco, R., Pistella, J., Salvati, M., Ioverno, S., \& Lucidi, F. (2018). Sports as a risk environment: Homophobia and bullying in a sample of gay and heterosexual men. Journal of Gay and Lesbian Mental Health, 22(4), 385-411. https:// doi.org/10.1080/19359705.2018.1489325

Benítez-Sillero, J. de D., Armada Crespo, J. M., Córdoba, E. R., \& Raya-González, J. (2021). Relationship between amount, type, enjoyment of physical activity and physical education performance with cyberbullying in adolescents. International Journal of Environmental Research and Public Health, 18(4), 1-12. https://doi.org/10.3390/ ijerph18042038

Bronfenbrenner, V. (1979). The ecology of human development: Experiments by nature and design. Cambridge, MA: Harvard University Press.

Callaghan, M., Kelly, C., \& Molcho, M. (2019). Bullying and bystander behaviour and health outcomes among adolescents in Ireland. Journal of Epidemiology and Community Health, 73(5), 416-421. https://doi.org/10.1136/jech2018-211350

Collot, A. L. \& Dudink, A. C. M. (2010). Bullying beyond school. Examining the role of sports. In S. R. Jimerson, S. M. Swearer, \& D. L. Espelage (Eds.), Handbook of bullying in schools: An international perspective. (pp. 235-248). Oxfordshire, UK: Routledge/Taylor Francis Group.

Danes-Staples, E., Lieberman, L., Ratcliff, J., \& Rounds, K. (2013). Bullying experiences of individuals with visual impairment: The mitigating role of sport participation. Journal of Sport Behavior, 36(4), 365-382.

Evans, B., Adler, A., MacDonald, D., \& Côté, J. (2016). Bullying victimization and perpetration among adolescent sport teammates. Pediatric Exercise Science, 28(2), 296-303. https://doi.org/10.1123/pes.2015-0088

Flores, G., Prat, M., Ventura, C., \& Ríos, X. (2021). "I was always made fun of for being fat": First-hand accounts of bullying in children's football. Physical Education and Sport Pedagogy, 26(6), 549-551. https://doi.or$\mathrm{g} / 10.1080 / 17408989.2020 .1826918$ 
Gendron, M. \& Frenette, E. (2016). Peer aggression in soccer (football) in Quebec among U12 to U18 elite players of sport study programs: Differences according to age and player's role. Staps, 2(112), 49-66. https://doi.org/10.3917/ sta.112.0049

González-Cabrera, J., Sánchez-Álvarez, N., Calvete, E., León-Mejía, A., Orue, I., \& Machimbarrena, J. M. (2020). Psychometric properties of the triangulated version of the European Bullying Intervention Project Questionnaire: Prevalence across seven roles. Psychology in the Schools, 57(1), 78-90. https://doi.org/10.1002/pits.22320

Hulteen, R. M., Smith, J. J., Morgan, P. J., Barnett, L. M., Hallal, P. C., Colyvas, K., \& Lubans, D. R. (2017). Global participation in sport and leisure-time physical activities: A systematic review and meta-analysis. Preventive Medicine, 95, 14-25. https://doi.org/http://dx.doi.org/10.1016/j.ypmed.2016.11.027

Iida, P. C. \& McGivern, C. T. (2014). Creating an LGBTQ+-affirming locker room: Education for prevention. Multicultural Education, 26(2), 17-22.

Jones, G. J., Edwards, M. B., Bocarro, J. N., Bunds, K. S., \& Smith, J. W. (2016). An integrative review of sport-based youth development literature. Sport in Society, 20(1), 161-179. https://doi.org/10.1080/17430437.2015.1124569

Kentel, J. L. \& McHugh, T. L. F. (2015). "Mean mugging": An exploration of young aboriginal women's experiences of bullying in team sports. Journal of Sport and Exercise Psychology, 37(4), 367-378. https://doi.org/10.1123/ jsep.2014-0291

Kerr, G., Jewett, R., MacPherson, E., \& Stirling, A. (2016). Student-athletes' experiences of bullying on intercollegiate teams. Journal for the Study of Sports and Athletes in Education, 10(2), 132-149. https://doi.or$\mathrm{g} / 10.1080 / 19357397.2016 .1218648$

Logan, K., Cuff, S., LaBella, C. R., Brooks, M. A., Canty, G., Diamond, A. B., Hennrikus, W., Moffatt, K., Nemeth, B. A., Pengel, K. B., Peterson, A. R., Stricker, P. R., Bagnall, D. W., Solomon, J., Halstead, M. E., Faigenbaum, A. D., Gregory, A. J. M., Kinsella, S. B., \& Emanuel, A. (2019). Organized sports for children, preadolescents, and adolescents. Pediatrics, 143(6). https://doi.org/10.1542/peds.2019-0997

Martínez, J. R. (2016). Construcción y validación de un cuestionario para medir el bullying entre iguales en los deportes de equipo. Unpublished doctoral thesis, Universidad de Las Palmas de Gran Canaria, Spain.

McCloughan, L. J., Mattey, E. L., \& Hanrahan, S. J. (2015). Educating coaches on their role in the prevention of homophobic bullying in adolescent sport. International Sport Coaching Journal, 2, 317-329. https:/doi.org/10.1123/ iscj.2014-0155

Menesini, E., Tassi, F., \& Nocentini, A. (2018). The competitive attitude scale (CAS): A multidimensional measure of competitiveness in adolescence. Journal of Psychology \& Clinical Psychiatry, 9(3), 240-244. https://doi.org/10.15406/jpcpy.2018.09.00528

Mishna, F., Kerr, G., McInroy, L. B., \& MacPherson, E. (2019). Student athletes' experiences of bullying in intercollegiate sport. Journal for the Study of Sports and Athletes in Education, 13(1), 53-73. https://doi.or$\mathrm{g} / 10.1080 / 19357397.2019 .1581512$

Modecki, K. L., Minchin, J., Harbaugh, A. G., Guerra, N. G., \& Runions, K. C. (2014). Bullying prevalence across contexts: A meta-analysis measuring cyber and traditional bullying. Journal of Adolescent Health, 55(5), 602-611. https:// doi.org/10.1016/j.jadohealth.2014.06.007

Monks, C. P. \& Coyne, I. (2011). Bullying in different contexts. Cambridge, UK: Cambridge University Press. https:// doi.org/10.1017/CBO9780511921018

Moore, S. E., Norman, R. E., Suetani, S., Thomas, H. J., Sly, P. D., \& Scott, J. G. (2017). Consequences of bullying victimization in childhood and adolescence: A systematic review and meta-analysis. World Journal of Psychiatry, 7(1), 60-76. https://doi.org/10.5498/wjp.v7.i1.60

Nery, M., Neto, C., Rosado, A., \& Smith, P. K. (2019). Bullying in youth sport training: A nationwide exploratory and descriptive research in Portugal. European Journal of Developmental Psychology, 16(4), 447-463. https://doi.org/ https://doi.org/10.1080/17405629.2018.1447459

Nery, M., Neto, C., Rosado, A., \& Smith, P. K. (2020). Bullying in youth sports training. Oxfordshire, UK: Routledge/ Taylor Francis Group.

Nery, M., Ventura, C., \& Stirling, A. (2021). Bullying in sport. In P. K. Smith \& J. O’Higgins (Eds.), The Wiley-Blackwell handbook of bullying: A comprehensive and international review of research and intervention (pp. 181-199). Hoboken, NJ: Wiley Blackwell.

Olweus, D. (1978). Aggression in the schools: Bullies and whipping boys. London, UK: Hemisphere.

Olweus, D. (2006). Conductas de acoso y amenaza entre escolares ( $3^{\text {rd }}$ ed.). Madrid, Spain: Morata.

Olweus, D. (2013). School bullying: Development and some important challenges. Annual Review of Clinical Psychology, 9(1), 751-780. https://doi.org/10.1146/annurev-clinpsy-050212-185516 
Prat, M., Flores, G., Ríos, X., \& Ventura, C. (2020). Bullying en el fútbol infantil: La mirada de las familias y de los entrenadores. Movimento, 26(e26032). https://doi.org/10.22456/1982-8918.97195

Sánchez-Romero, E. I., Verdaguer, F. J. P., Borràs, P. A., \& García-Mas, A. (2020). Systematic observation of the verbal behavior of families of youth athletes in grassroots and team sports. International Journal of Environmental Research and Public Health, 17(4), 1-10. https://doi.org/10.3390/ijerph17041286

Smith, P. K. (2018). Commentary: Types of bullying, types of intervention: Reflections on Arseneault (2018). Journal of Child Psychology and Psychiatry and Allied Disciplines, 59(4), 422-423. https://doi.org/10.1111/jcpp.12897

Smith, P. K. (2019a). Introduction. In P. K. Smith (Eds.), Making an impact on school bullying: Interventions and recommendations (pp. 1-22). Oxfordshire, UK: Routledge/Taylor Francis Group.

Smith, P. K. (2019b). Research on cyberbullying: Strenghts and limitations. In L. G. Heidi (Eds.), Narratives in research and interventions on cyberbullying among young people (pp. 9-27). New York, NY: Springer International Publishing. https://doi.org/10.1007/978-3-030-04960-7_2

Steinfeldt, J. A., Vaughan, E. L., LaFollette, J. R., \& Steinfeldt, M. C. (2012). Bullying among adolescent football players: Role of masculinity and moral atmosphere. Psychology of Men and Masculinity, 13(4), 340-353. https://doi. org/10.1037/a0026645

Stevens, G. W. J. M., Boer, M., Titzmann, P. F., Cosma, A., \& Walsh, S. D. (2020). Immigration status and bullying victimization: Associations across national and school contexts. Journal of Applied Developmental Psychology, 66(101075), 1-12. https://doi.org/10.1016/j.appdev.2019.101075

Tilindienè, I., Rastauskiené, G., Zalys, L., \& Valantiniené, I. (2008). The influence of gender and sports on the expression of bullying experienced by teenagers between 12-15 years old and their bullying peers. Socialiniai tyrimai: Social Research, 3(13), 179-185.

UNESCO. (2019). Behind the numbers: Ending school violence and bullying. Paris, France: UNESCO, Education Sector. https://unesdoc.unesco.org/ark:/48223/pf0000366483

Volk, A. A. \& Lagzdins, L. (2009). Bullying and victimization among adolescent girl athletes. Journal of Athletic Training, 11, 13-31.

Vveinhardt, J. \& Fominiene, V. B. (2019). Gender and age variables of bullying in organized sport: Is bullying "grown out of'? Journal of Human Sport and Exercise, 15(4), 1-16. https://doi.org/10.14198/jhse.2020.154.03

Vveinhardt, J., Fominiene, V. B., \& Andriukaitiene, R. (2019a). Encounter with bullying in sport and its consequences for youth: Amateur athletes' approach. International Journal of Environmental Research and Public Health, 16(23), 1-17. https://doi.org/10.3390/ijerph16234685

Vveinhardt, J., Fominiene, V. B., \& Andriukaitiene, R. (2019b). "Omerta” in organized sport: Bullying and harassment as determinants of threats of social sustainability at the individual level. Sustainability, 11(9), 2474. https://doi.or$\mathrm{g} / 10.3390 / \mathrm{su} 11092474$

Vveinhardt, J., Fominiene, V. B., \& Jesevičiūtė-Ufartienė, L. (2018). Prevalence of bullying and victimization in amateur sport: A case of Lithuania. In 11th Annual International Conference of Education, Research and Innovation (pp. 8238-8244). Seville, Spain: ICERI 2018. https://doi.org/https://doi.org/10.21125/iceri.2018.0492

Vveinhardt, J., Komskiene, D., \& Romero, Z. (2017). Bullying and harassment prevention in youth basketball teams. Transformations in Business and Economics, 16(1), 232-251.

This is Open Access article distributed under the terms of CC-BY-NC-ND 4.0 International License. 